\title{
Disassembling and Reassembling a Sports Talent
}

\author{
By \\ Jesper Stilling Olesen, Jens Christian Nielsen \& \\ Dorte Marie Søndergaard
}

\begin{abstract}
This article is rooted in an understanding of talent as something you do rather than something you either are or have. Talent is hereby seen as a phenomenon that comes into being through actions, rather than as an individualized, inherent capacity. Our perspective is informed by new materialist concepts that analyse talent development as an assemblage. Based on a case study focusing on Jamie, an injured badminton player, we argue that talent development produces a number of affects: it translates potential into a singular talent; it enables the conversion of talent into expertise; it turns doubt into belief; and it impedes other ways of coming into being for the athlete under development. The study provides insight into the micropolitics of talent development and into the ontological, pedagogical and ethical implications for the athlete and all the other actors entangled in a talent assemblage.
\end{abstract}

Keywords: Talent, talent development, enactment, assemblage, affect, micropolitics, new materialism.

Stilling Olesen, Jesper, Jens Christian Nielsen \& Dorte Marie Søndergaard: "Disassembling and Reassembling a Sports Talent", Culture Unbound, Volume 12, Issue 2, 2020: 311-331. Published by Linköping University Electronic Press: http:// www.cultureunbound.ep.liu.se 


\section{Introduction}

On perusal of Jamie's track record, one would be inclined to declare him a talent: as a junior, he has won three national badminton championships in singles, doubles and mixed doubles; he has played for the national team, and he has participated in international competitions, won medals in various elite tournaments in Denmark and attended a special class for elite athletes for three years. This perception of Jamie as a talent is rooted in a common understanding of talent as something that the individual athlete either has or is. The fact that Jamie has excelled by winning competitions and national championships at some point in the past indicates that he has talent and that he is therefore likely to win again in the future.

In everyday discourse, as well as in research on talent, we tend to think of talent as an ontological reality. However, Jamie's story, as recounted during our interviews, raises fundamental questions about the nature of talent and the extent to which it is the sole property of the individual athlete. The first of these questions concerns how long an athlete can continue to $b e$ a talent-from whose perspective and within which systems-when he or she is unable to do talent. At what point does he or she become someone who was a talent rather than someone who is a talent? More radically, it can be asked whether it is possible to be a talent if one does not have control over the talent of oneself and if it becomes clear that there are more people involved in the process of talent production. If this is the case, whose talent is it and who is in charge of managing it?

In this article, we want to show that the existence of talent is dependent on others besides the athlete himself and that these actors have the power to determine whether a given talent gains existence. It has already been argued in educational literature that talent is socially constructed. Csiksentmihalyi et al. (1993) defined talent as a seal of approval we affix to traits that have a positive value in the particular context in which we live. The social dimension to this definition is particularly relevant to the domain of sports. It is clear that sporting talent does not exist in a vacuum but in reality and is only labelled as talent when it is valued and approved by the participants in the domain in which it exists. From this definition, it would seem that talent must be understood as an essentially relative phenomenon. Even though many researchers accept Csiksentmihalyi's basic assumptions in principle, some of the literature concerning sports talent treats talent as an ontological reality, for example, in discussions concerning the origins of talent. The nature versus nurture debate has been highly influential within certain sections of this research field, as reflected in a number of the dominant models of talent development (e.g. Côté 1999; Gagné 1993 \& 2000; Wylleman, Alfermann \& Lavallee 2004, Stambulova \& Wylleman 2014). In different ways, these models make a strong distinction between individual properties, such as intellectual, creative, social and motor skills, and environmental factors, such 
as the physical, cultural and social environment, key figures within the talent domain, and special programmes, activities and services offered to individual sports talents. The last ten to fifteen years has seen a tendency within research to place greater emphasis on environmental factors (e.g. Alferman \& Stambulova 2007, Henriksen 2010), situating the athlete in an extensive and rather complex talent environment. Despite the high degree of complexity characterizing recent research on talent, a clear distinction between athlete and environment is still assumed. Who is or who has the talent is rarely disputed. It is generally placed with the individual athlete who receives varying degrees of support from personal, organizational and societal actors (Baker, Cobley, Schorer \& Wattie (2017). Durand-Bush \& Salmela (2002) have criticized this polarization in how talent is understood as a dead end. There is a clear risk that dichotomous approaches to the study of talent will fail to capture the interplay between biology, environment, socially embedded meaning-making processes and the valorization of certain characteristics in the construction and maintenance of talent.

Meanwhile, research on talent has also shown an enduring interest in understanding the dynamic aspects of talent development and the interplay between the individual athlete and the key figures surrounding him or her. For instance, Ericsson, Krampe \& Tesch-Römer (1993) studied the development process as a series of competences that are systematically developed through deliberate practice, which leads the athlete to seek regular performance feedback from his or her teacher, coach or peers. Côtés highly influential sports-specific model of developmental phases describes the temporal development process that athletes undergo (Côté 1999 and Stambulova, Alferman, Statler \& Côté 2009). These phases are the sampling years, the specialization years and the investment years, with the relationship between play and training gradually changing as the athlete progresses towards the goal of expertise within a given sport. There are also a number of studies exploring the interplay between the sports talent and certain key figures such as the coach (Bloom 1985) and the athlete's family (Côté 1999, Helstedt 2005) that focus on how potential is transformed into expertise. These studies show that the coach's and family's respective roles and ways of acting change as the athlete progresses through the various developmental stages. Such studies are interesting because they indicate how the interaction between the athlete and other key figures results in functional changes in the roles they play. The boundary between athlete and environment thereby appears less clear-cut here than in the predominantly static models discussed above, but without due attention to the theoretical implications.

Another reason why it is important to consider the dynamic aspects of talent development is that talent represents future expertise. It is a fundamental problem for both researchers and practitioners that what they are looking to identify is 
something that does not yet exist: an athlete's potential. As pointed out by Régnier et al. (1993): "In defining human potentiality, we refer to that which exists in possibility, not actuality, whereas in testing procedures we evaluate that which exists in actuality not in possibility" (Régnier et al. 1993: 290). The identification, selection and development of talent is therefore based on an assessment of whether, over time, a given potential can be developed into expertise. So far, it has not been possible to identify particular characteristics of raw talent that can accurately predict excellence with regard to the fully-developed athlete's performance level (Bloom 1985, Bartmus et al. 1987, Tranckle \& Cushion 2012). Furthermore, a lack of competence in one area can, to some extent, be compensated by a high level of competence in another area (Bartmus et al. 1987). This means that talent development is dependent on qualified guesswork. Coaches and others responsible for selecting and developing sports talents therefore have to interpret indicators or signs of talent. Among the indicators identified in the literature are: that the athlete has made a commitment to a domain of elite sport (Walters \& Gardner 1986, Meyer \& Allen 1991, Scanlan et al. 1993, Côté 1999); that the athlete progressively develops competence (Ericsson, Krampe \& Tesch-Römer 1993, Gagné 2003, Stambulova, Alferman, Statler \& Côté 2009); and that the sport is performed at the highest level relative to the athlete's age (Bloom 1985, Côté 1999, Abbott \& Collins 2004), which is seen as evidence that the fully-developed athlete will be able to compete at the elite level. Of course, such indicators are subject to greater uncertainty the earlier an athlete is selected for talent development. As a result, an integral part of any talent development practice is faith and doubt concerning an athlete's potential-both for those tasked with supporting the athlete's development and in terms of the athlete's belief in his or her own talent. There is an inherent risk that athletes who do not exhibit the right signs at the right moments will be rejected. This has been termed "talent elimination" (Régnier et al. 1993) and described as an issue of physical maturity, for example affecting late developers (Malina 1997). The negative consequences of being rejected due to a misinterpretation of talent indicators is inadequately discussed within the literature.

Before returning to Jamie's story, we will present the elements of new materialism from which we draw inspiration and their implications for how we understand talent and talent development.

\section{New Materialism as a Perspective on Talent and Talent Development}

In this article, we introduce a number of key neo-materialist concepts to a theoretical and empirical field where they have not previously been applied in order to gain new analytical insights and understandings of the phenomena of talent and talent development.

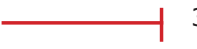


Our approach to talent development focuses on collective efforts to produce sports talents. As such, we regard talent as an effect of actions in an assemblage (Deleuze \& Guattari 1987). As already suggested, this differs somewhat from common ways of understanding talent as something an individual either has or is. These perspectives understand talent as a substance: as something that is present a priori and which one can acquire knowledge of through observation. Such understandings are widespread, concealing some of the work that athletes and various other actors who contribute to talent development must do to produce a talent. Instead, our approach to talent and talent development focuses on the processes that lead some athletes to become talents. We investigate talent as something that is done, performed or enacted (Mol \& Law 2004).

This analytical strategy shifts the perspective from the individual to an assemblage and focuses on the practices that produce, reiterate and sometimes even dissolve talent. Assemblage is a translation of the French agencement, a concept developed by Deleuze and Guattari (1987). The translation captures the relational character of assemblages and that they consist of a number of heterogeneous entities that are tied together in an agential whole. The heterogeneous entities that connect in an assemblage are fundamentally unstable and malleable. It therefore requires work to maintain the connections between them and stabilize them so that they appear unified (Law 2009). Mol and Law (2004) illustrate the work required to keep the human body assembled as a functional entity using the case of a person with diabetes. The diabetic cannot survive without the addition of substances from the outside world. The talented body likewise represents an example of an entity that only reaches full existence through interaction with other actors.

On the one hand, it is characteristic for talents that they have something special; for example, certain physical attributes or a high current skill level. On the other hand, they know that they lack something if they are to reach the goal of excellence. The talented body is therefore incomplete compared to an ideal of excellence within a particular sport. Unlike those with diabetes, who would die without the external administration of insulin, sporting talents do not risk losing their lives. However, the analogy does apply to the extent that, without a concerted effort to continue their development, they risk falling out of the talent category, thus losing their existence as a sporting talent (Skrubbeltrang, Nielsen \& Olesen 2016). Where insulin is a means for the diabetic to regulate blood sugar levels, training is an important tool for ensuring the continued existence of the sporting talent in a talent development environment.

Just as people with diabetes exist in interaction with other human and non-human actors, athletes become talents in interaction with coaches, teammates, competitors, practice sessions, exercise equipment, training plans, etc. We will 
therefore analyse the sporting talent as an incomplete subject who has to perform talent in such a way that he/she becomes recognizable as a talent within the talent assemblage (Bruun Jensen 2010). As sketched out in the section above, some of the important indicators of sporting talent have to do with being committed to elite sport, being on a progressive learning trajectory and aiming at an excellent level of performance. However, we will not investigate these indicators as individual attributes. Instead, we apply a relational perspective on talent development, which allows us to explore the collective enactment of commitment, progression and excellence. This emphasizes that agency is linked to the overall assemblage and not to the constituent actors-human or non-human. Deleuze and Guattari suggest the concept of 'affect' instead of agency as a term for the capacity accumulated in an assemblage to affect its actors, change their conditions or alter the relationships between them (Deleuze \& Guattari, 1987).

Once an assemblage has become stable, all the work that went into bringing the various actors together becomes blackboxed (Latour 1999). This is what allows the athlete to appear to be an individual person with a talent. Latour explains this appearance as a punctualizing effect, allowing somebody to become a spokesperson - someone who speaks on behalf of the entirety of the network (Latour 2003). Usually, we assume the spokesperson to be the athlete him or herself, who, with support from numerous helpers (human as well as non-human), is able to excel within the sport. However, in some cases it becomes less evident who gains the authority to speak on behalf of the talent. In our analysis of the talent associated with Jamie, we therefore take note of who speaks on behalf of the talent and will slightly adapt Latour's concepts so that we can also listen out for whether there is more than one voice speaking. Drawing inspiration from Davies (2014), we will thereby also ask which voices are heard and whether there are certain voices that are ignored. She distinguishes between two types of listening: listening-as-usual and emergent listening. Listening-as-usual is an act of listening that serves to adapt what we hear to what we already know. It is a form of listening that produces repetition, predictability and stability. Emergent listening, meanwhile, involves acts of listening that open new ways of thinking and being. As such, Davies regards change as tied to our ability and will to hear that which has not yet been articulated and to use one another as resources in a mutual process of becoming. Athletes are expected to develop a large capacity for action through their will to achieve a specific goal. Davies highlights an alternative opportunity for individuals to gain increased capacity for action through joint emergent listening with others. Both forms of listening are legitimate within a talent assemblage, but it can have critical consequences for an athlete if one type becomes overly dominant. 


\section{Methods to Examine Talents in the Making}

When researchers study talents, they often focus on senior elite athletes and inform their analysis by looking back over their careers from a position where the athlete's goal of breaking through to the senior elite has been reached (i.e. Storm, Henriksen \& Christensen 2012; Debois, Ledon \& Wylleman 2015). From that position, the researchers present a retrospective narrative in which the talent has always been present. Should the athlete have faced adversity on the way to achieving this goal, it is presented in the form of difficult transitions that he has overcome by virtue of his unique talent. However, studying talent in the making reveals the fragility of the phenomenon. It offers direct insight into how talent is created and shaped and produces knowledge about the actions that determine whether talents develop and flourish or fade and disappear. A study of talents in the making therefore requires the researcher to follow athletes for an extended period.

Our analysis draws on empirical material that forms part of a larger study of sports classes in Denmark (Nielsen et al. 2017). The overall study consists of two quantitative surveys and a qualitative ethnographic study of four sports classes situated in four different municipalities in Denmark. The students who are selected for these classes are aged 12-15. In the ethnographic study, we followed 80 students during the last two years of lower secondary school. They were interviewed two or three times during the school years 2013/14 and 2014/15. In addition to these interviews, informal conversations with students took place during fieldwork at the schools and at the associated elite sports clubs (Nielsen et al. 2017). We gained access to the sports classes through municipal and school sports coordinators. Parents were informed and asked to consent to their child's participation in the study. We began the first round of interviews by presenting the study's purpose and the subsequent process, telling the young athletes that we wanted to take part in their classes and accompany them to club training sessions. We also informed them that anything they said would not be shared with others and guaranteed full anonymity in the project's reports and other publications. They were notified of their right to withdraw from the project at any time. In cases where informants provided confidential information, we confirmed that their statements would be treated as such. The interviews generally focused on the relationship between, on the one hand, the athlete's recognition of his own talent, his experience of his own progression and his expectations for the future and, on the other hand, actors in the talent development environment that affect the athlete's career.

In the analysis we present below, we have selected the story of an athlete, Jamie, that challenges prevailing notions of what a talent is, because it is apparent that when Jamie's ability to perform fluctuates, multiple actors, and not just Jamie 
himself, are involved in the maintenance of his talent. When we have selected only one informant for this article, it is because we want to attend to the multiple relations in which he entangles. In addition to interviewing Jamie three times, we also interviewed his parents and other key actors in the talent environment. Jamie was also part of the participant observations we conducted in his sports class.

The theoretical concepts presented above are introduced to help understand the dynamics involved in the production and reproduction of talent.

\section{Analysis}

We mentioned earlier that, as a boy, Jamie lived up to every expectation in terms of how to do talent. He swept the board in national competitions in his age group, which convinced the national team that he had the potential to participate in international competitions. He was also awarded a place as a talent in a sports class, based on an assessment by his local club in collaboration with the national federation, Badminton Denmark, that Jamie had the talent to join the ranks of the senior elite. However, shortly after joining the sports class, he was injured. For three months, Jamie could barely walk. Nobody was able to accurately ascertain what was wrong. Why Jamie was suddenly unable to enact talent was a riddle.

In the following analysis, we will examine what happens when the individual athlete cannot enact talent and how the different parts of the talent assemblage react. We begin by showing how the talent disassembles in reaction to Jamie's condition and how it gradually reassembles in a new talent assemblage that allows Jamie to become a talent again.

\section{Disassembling a National Talent}

Thinking with new materialist concepts, we first of all ask what athletes should do to occupy and maintain a position as a talent in a talent assemblage. Callon uses the term obligatory passage points to refer to the entrance through which actors must pass in order to be allowed a place in a given assemblage (Callon 1984). We previously identified three key performances if an athlete is to convincingly pass as a sports talent: The athlete must demonstrate commitment to do whatever necessary to become part of the elite, display progressive development of athletic skills, and aim for an excellent performance level in the senior ranks.

The athlete who is able to perform this combination of qualities will have the opportunity to pass the obligatory passage point into a desirable talent assemblage. We can regard the national team as such an assemblage at the top of the overall elite network of clubs across Denmark. When Jamie was a U13 player, he had no trouble passing the obligatory passage point to one of the 10-12 positions available in the national team squad. Later, when he got injured, he could not deliver what 
counts as an excellent performance in a national team context. The national team did not find his performance sufficient, so after a while he lost his place on the team.

If we regard the national team as an assemblage, it is not simply a case of Jamie not performing as required, Badminton Denmark (the national federation) also withdrew one of the 10-12 national talent positions they administer from Jamie and awarded it to another player who they considered better able to enact talent at an elite national level. Thus, talent also appears to be on loan rather than something permanent. When Badminton Denmark lent Jamie the position, he had access to the affective forces that enable an athlete to become a national talent. However, when Badminton Denmark terminated the loan, the opportunity shifted to another player. In the next section, we look at Jamie's efforts, with the support of numerous other actors at club level, to reassemble himself as a national talent.

\section{Talent Enacted as Commitment}

During the period when he did not participate in practice sessions, Jamie's engagement with the talent was reduced to a strong commitment to stage a comeback and it was this commitment that the talent assemblage listened to and acted upon. Let us look at how Jamie enacts talent during his long period of injury. The work involved is extensive for both Jamie and his parents:

I: So if you were to say who has helped you through that period, would it then be the physical therapist, your trainer from the club and the sports psychologist who has been a little involved?

J: Yes.

I: what about your parents, how did they help you with that?

J: They have taken me to one physiotherapist after the other and they have taken me to physicians and foot specialists, spine specialists and 100000 other people.

I: You have come far around.

J: We have been everywhere you can go.

I: It was also because it was difficult to find out what was going on? 
J: I was scanned twice as well. They couldn't really find anything.

I: Then you can go round to all kinds of experts.

(First interview, April 2014).

While Jamie is injured, he does not turn his attention to other interests, nor does he begin to spend more time on schoolwork in order to pursue other ways of being. His commitment remains uniquely tied to a badminton career, which he intends to resume as soon as he has recovered from the injury.

The case shows that, with the support of a large number of different actors, Jamie reassembles as a badminton talent. Jamie mentions during our three interviews that he had two MRI scans at the hospital; he has seen a spine specialist; he has seen a dietician; he has seen two different prosthetists to get inserts made for his shoes; he has had special bandages made for his knees; he has consulted numerous physiotherapists; and he has had three sessions with a sports psychologist. Furthermore, his coach, physiotherapist and the sports psychologist have held a number of interdisciplinary meetings to prepare and coordinate their support.

What we see is a comprehensive talent assemblage entailing machines, scanners and other artefacts, as well as a changing constellation of humans working to enable Jamie's body to re-engage actively in the extensive assemblage that produces talent. That the assemblage was so comprehensive has to do with the difficulty in ascertaining why Jamie's body sometimes refused to cooperate in terms of doing talent. Yet, it also indicates that parts of the talent assemblage still believed in Jamie as a possible co-producer of talent. The past seems to play a significant part in the maintenance of Jamie's status as a talent. We will return to this point in our discussion of the micropolitics of the talent assemblage.

\section{Talent Enacted as Commitment and Progression}

One of the things Jamie himself highlights as helpful in re-establishing him in a talent-producing flow is the dialogue with his physiotherapist. The physiotherapist listens to his body in a different way than his coach at the club. She recommends that, for a while, Jamie should focus more on physical training than playing competitive badminton:

I: If you were to look back on what you have been through, where things are going better now, what would you say that has helped you. What has helped you get through or partially through this injury period? 
J: I have worked closely with a physical therapist. I have had lots of exercises that he has given me, which have been in my program. I had to think more about training myself than playing badminton. That has helped some, I think.

I: Yes, so that is kind of the primary. Then you've followed that program there. So you simply had a different focus. Instead of focusing on badminton, you have focused on getting stronger and better. How long have you had that focus?

J: Half a year's time. There I haven't played that much. Now here for the past six months I have played quite a lot again.

I: And so have you been better able to start focusing on badminton now?

J: Yes. I think so.

(Third interview, May 2015.)

The physiotherapist also served as a mediator between Jamie and his club coach. The physiotherapist spoke on behalf of Jamie's body and convinced the coach that Jamie should not compete for a period to allow him to concentrate on physical recovery and rehabilitation. For a while, it was possible to base Jamie's progression on his current proficiency level instead of the performance level required of elite players. This was a decision that came at a certain cost to the club, because Jamie did not earn them points when he was not taking part in competitions. The decision to exempt Jamie from competition could therefore have a negative impact on the club's performance in tournaments and, in a slightly longer perspective, on the club's ranking as a talent environment. As Jamie puts it: (Club name ed.) drops quickly (third interview, May 2015).

\section{Talent Enacted as Commitment, Progression and Excellence}

In addition to the reassembly of Jamie's body, the coach chose to introduce Jamie's precarious capacity to play to a slightly altered talent assemblage. After six months of focus on exercise, he returns to competitive matches again, albeit less intensively than before his injury. For a while, he concentrates entirely on men's and mixed doubles. It is worth noting that his coach still paired him with other talented players in men's and mixed doubles. Otherwise, he would not be part of a talent-producing assemblage with sufficient affect to demonstrate that he is a talent and to experience himself as a player who can go a long way in tournaments.

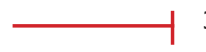


With these adjustments of the talent assemblage, Jamie gradually again became able to do talent at an excellent level. The assemblage created an affect that was so strong that Jamie and the other players regained the belief that he could win again. Even Badminton Denmark invited him back to the national team squad. When he played at the national championships, he reached the latter stages of the tournament. Unfortunately, he then suffered another injury, this time to his cruciate ligament:

J: It looked good until a week ago, when I was at the championships and was doing fine. Good chance of medals. And then I play the third match and I jump up and come down and sort of twist my knee. I had to withdraw. So that kind of sucked. (...) And the guys who ended up winning this thing, we beat them two weeks before. So that's a bit annoying (third interview, May 2015).

With that, Jamie's body again leaves its place in the talent assemblage.

We have described how Jamie gradually recovered from an injury to become a talent among the badminton elite again. However, his condition did not vanish; his knees have improved, but he still has chronic pain. So what changed and what caused the pain to become less significant? The change appears to be the result of a number of extensions of Jamie's body, combined with some adjustments in the talent assemblage that lends talent to selected badminton players. By virtue of footwear, bandages, a special knee training programme, a non-singles competition programme and Jamie's coach, physiotherapist, psychologist and parents working together to coordinate his rehabilitation, Jamie is able to get his body into collaboration with the talent assemblage that produce an affective flow which enables him to win again.

\section{A Tailor-made Assemblage of Talent}

We will now look more closely at the connections comprising the new talent assemblage that makes it possible to produce talent with Jamie. First, Jamie demonstrates an extremely high degree of commitment; something which is crucial in relation to elite sport. He prioritizes sport over school. For example, he says that his parents place greater importance on school than he does. However, commitment is relational. As the scope and complexity of the talent assemblage surrounding Jamie shows, there are many actors willing to engage in reassembling Jamie as a talent-producing actor. The various actors commit themselves for different reasons. Jamie's parents, for example, explain that they want their son to be happy again. With Jamie's commitment to badminton overriding all other 
activities, the path to their son's happiness seems to them to be inextricably linked to badminton. Other actors are connected to the assemblage by money; for example, the prosthetist, whom Jamie's parents pay, and the sports psychologist paid for by the municipality. Another group of actors contribute because, in their positions at the club, they need athletes with the potential to produce excellent performances, and they believe that Jamie can come to enact talent again. Without players like Jamie, the club loses its status as an elite club and its eligibility to receive funding for talent development. The players who collaborate with Jamie do so because they are ambitious and think they can win badminton matches together. Jamie is thus surrounded by a large number of actors who hold a position in the talent assemblage open to him for various reasons.

The second element of doing talent, progressive development, is not an individual endeavour either; rather, it is an effect of interactions that take place in an assemblage. In Jamie's case, there seems to be no consensus about what his current performance level is. His early success as a youth player indicates that the current performance level is among the national elite. However, his physical condition in the years that followed suggests a significantly lower current performance level as the basis for his development.

The base level for Jamie's progression was determined by an agreement between Jamie's club coach, his physiotherapist and a sports psychologist. Jamie was primarily an observing and enacting witness in this process. The various parties agreed that, for a period, Jamie's development had to be on the terms his body dictated and take the form of basic training. Thus, progression is an effect of exchanges between heterogeneous actors in an assemblage where the body has a seat at the table with the opportunity to veto any decision if it experiences pain or gets an acute injury.

In elite sports, victory is what counts in determining an excellent performance, at least in principle. However, when it comes to talent development, it is debatable whether excellence is something to be performed during the junior years or first in a distant future when the athlete eventually breaks through to the senior elite. Many coaches consider it more beneficial for young athletes to focus on winning as a senior than as a junior (see e.g. ATK 2.02016 ). However, there are other actors present in talent assemblages, human as well as non-human, who pull young athletes in the opposite direction; for instance, tournament structures requiring that players play and win lots of matches if they are to avoid being relegated from a prestigious league. In Jamie's case, a reduced tournament programme is compiled, meaning that he only needs to perform excellently in men's and mixed doubles. This can be regarded as a compromise with the intention of both listening to the club's need to gain points and listening to Jamie's body that is not yet ready for the full challenge of competitive badminton. 
The analysis thus shows that not only does the athlete have to adjust to a new bodily condition, for instance resulting from an injury; the entire talent assemblage has to reassemble in a way that creates a talent position befitting the transformed bodily element of the assemblage.

\section{The Affect Economy of the New Talent Assemblage}

Now we will turn our attention to the other actors within the talent assemblage and consider who speaks on behalf of the talent and how they listen to Jamie. That there are so many actors who still consider Jamie to be talented and are willing to supply a relatively large amount of resources to find out what is wrong and help him realize the talent is probably because he has shown very strong signs of talent early in his career. The points he has gained for the club, the gold medals he has won and the photograph of Jamie as a young player with three medals around his neck which stands in Jamie's family's living room all signal that the talent is real. These signs connect the past and the present. They become actors themselves with the ability to affect others, including Jamie. They help to mobilize new actors and recruit them to the assemblage, while at the same time sealing Jamie's destiny as talent. Eventually, his badminton talent defines Jamie. It appears as if it is badminton he has a talent for rather than anything else.

This talent assemblage is designed to listen to a certain kind of potential; namely the potential to reach the elite within a particular sport. It proves extremely effective in maintaining faith in the talent and in dismissing any doubts. That does not mean that the individual human actors who are part of the assemblage cannot doubt the extent of the talent or question whether a sports career is the right choice for Jamie, but as a collective, the assemblage mutes any possible doubt.

Jamie, for example, doubted his own ability during the periods when his condition prevented him from training and playing matches. When he was unable to do talent, he lost the sense of how good he is at playing badminton, as reflected in his surprise over his own performance when he does come back:

J: Funnily enough, I could already be among the best in Denmark. I became number two in the first tournament and won the next one.

I: That was not too bad.

J: It was a little strange (first interview, April 2014) 
The phrases "funnily enough" and "it was a little strange" indicate that, during this period, Jamie did not have a clear sense of his connection to the talent assemblage and the affective flows it produces. However, the fact that the talent assemblage maintained the connection and the faith in Jamie's talent enabled him to return to the badminton court and, through playing, reconnect with the talent.

Jamie was not the only one who, during one-to-one conversations, expressed doubt as to whether the talent is still there. The municipal sports coordinator also stated that he was unsure whether it was a good idea to maintain Jamie's status as an injured sports talent. He emphasized the absurdity in that Jamie had yet to participate in a single training session since joining the sports class. Despite his doubts, he helped Jamie recover as sports talent by allocating money for a sports psychologist to look for possible non-physiological explanations for the pain Jamie had in his knees. Jamie's father was also in doubt as to whether elite badminton is good for his son. He explained that Jamie was frustrated and that, in spite of their great effort, they could not find a solution to the problem. What he wanted more than anything was for Jamie to be happy again. For him, Jamie's happiness was not necessarily dependent upon badminton, but the family felt obliged to support the efforts to maintain Jamie's position within the assemblage as Jamie himself was adamant to do so and showed no interest in other potential avenues of becoming.

Only when we talked to Jamie one week after he had suffered a new injury at a major tournament did he express some doubt that countered the affective flow of the talent assemblage.

I: How long do you have the strength to keep doing this?

J: But then, that's hard to say. I really want to play. After all, I hope it stops at some point. (...) But then you start to believe... or not believe it.

I: Yes, it must come to a turning point at some point.

$\mathrm{J}$ : Yes.

I: But I can understand how the hope is kept alive because when you get on the court, you are doing well - and surprisingly well considering how little you are able to train. So that's what keeps you going.

J: Yes.

(Third interview, May 2015.) 
The assemblage that was set up to help Jamie in his state of incompleteness possesses a particular ability to listen to Jamie's potential. It is immensely responsive to his ongoing development as an elite badminton player and ignores all other possibilities. The assemblage continuously expands, incorporating new actors who can listen to precisely what his feet need; what can relieve the pain in his knee; how to improve his body stability; how long breaks he needs; what format is best for him: mixed doubles, men's double or singles. It seems that, as the assemblage expands and the material-discursive forces it possesses improve in responding to Jamie as an incomplete badminton talent, it becomes increasingly incapable of hearing any doubts about the avenue of becoming that Jamie follows. Talent development is, with Deleuze and Guattari's words, a highly territorialized field, where the possibilities of becoming are specified in detail and locked to specific development goals (Deleuze \& Guattari 1987). Our analysis therefore raises an ethical question about when talent development is detrimental rather than beneficial-and for whom. This is certainly a well-known question in relation to talent development, but new materialist perspectives provide a fresh basis for its consideration. In a perspective where talent is uniquely linked to the individual, the question can be expressed as follows: How great is the talent and what is the individual athlete willing to sacrifice to realize it? In a new materialist view, the question will take a different form. In this way of understanding, the individual is not personally in control of the talent. The individual athlete has to become part of a talent assemblage that can enable the potential talent to emerge and gain existence. In order to reach the elite, the entire talent assemblage acts on the idea that the athletic potential is present. In Jamie's case, the assemblage takes the three gold medals he won as a very young player as an indication of this potential, ignoring the possibility that the human biological material may no longer be present. Perhaps the assemblage surrounding Jamie should have noticed and acted on his long history of injury as a sign of lack of talent, rather than focusing on the medals. Thinking with new materialist perspectives, the following questions can therefore be asked: Which voices become hearable within a talent assemblage and which voices are ignored? How are the adults within a talent assemblage attuned to listen to emergent voices that fall outside the preferred trajectory of becoming? Who is responsible for any possible mishearing when an assemblage of actors instead of an individual athlete maintains the assumption of talent?

\section{The Micropolitics of Talent Development}

Our analysis of the badminton player Jamie's efforts to become a talent offers an insight into what can be called the micropolitics of talent development. This is a concept that can be traced back to Annemarie Mol's development of the term 
'ontological politics', combining ontology and politics (Mol, 1999). The term suggests that reality does not supersede the everyday practices in which we interact with the terms of our being; on the contrary, the conditions take shape through these practices. The term 'politics' thus emphasizes the procedural nature of becoming and the indefinite nature of the design of reality. Our interest in the micropolitics of talent development is precisely to gain insight into the affect that is built up in specific talent assemblages, the forms the processes take and what the affect enables the actors who are designated as talents to do (Deleuze \& Guattari 1987).

The talent assemblage we have studied produces a variety of affects. One affect is that any doubts are transformed into belief in Jamie's potential, despite the fact that, for several months, he was unable to play badminton or even walk and no one was able to explain why. It may be tempting for an athlete to trade potential within multiple activities for talent within a single activity because the latter is a label that allows an athlete to enter an esteemed talent assemblage and receive a lot of attention and assistance to reach a shared goal. However, doing so can also be problematic because it may be at the expense of the opportunity to participate in other assemblages that open up other avenues of becoming. A talent assemblage seems to be highly territorialized, therefore placing severe limitations on potential being realized in ways other than as a particular kind of talent. The new materialist perspective thus contests the idea of talent development as a neutral event that simply supports the budding talent in his own endeavour. Talent development is an assemblage that is designed to spur and shape the existence of individuals in terms of committing an individual to elite sport, optimizing the individual's progression through practice, which is measured against an ideal of becoming part of the elite in the future. As such, the temporal dimension appears of particular interest in relation to talent development. Talent development forms a strong bond between the athlete's past actions, his or her current actions and the future goal of being able to perform at the highest level. As pointed out by Uprichardt (2008), it can be problematic if our concept of who a child is becomes tied to a particular anticipated future:

How we conceptualize something in the future may influence how we conceptualize it in the present. Furthermore, whilst our anticipation of the future may influence how we conceptualize something in the present, our anticipations may be wrong. Therefore, to base our constructions of what a child is primarily on what the child will be is problematic even if we accept that the future matters" (Uprichard 2008: 304). 
Jamie is thereby tied to a particular subjectivity through his dream of becoming the best badminton player in the future. But he is also tied to his past as a triple Danish national champion and various other merits, which simultaneously helps maintain the belief that he has talent even though he cannot play and seals his fate as the eternal badminton player.

\section{Ontological, Pedagogical and Ethical Implications for Talent Development}

Thus, talent development proves to be an intervention with far-reaching ontological, pedagogical and ethical implications for the athlete and all the other actors who are mobilized by a talent assemblage. The perspectives we have developed might inspire not only the ways athletes, talent developers and their organizations think and act, but also the practices they have developed to evaluate and adjust talent status and talent care. If the basis for the success of the assemblage, in terms of producing both good sporting results and satisfied and enthusiastic athletes, is a complex interaction, the attention of the assemblage's actors to such complex processes and their inherited spatiality and temporality will likely be major focus points, replacing a more limited focus on the production of results and medals. This implies a continuous assessment of whether the affective flow built up in talent assemblages actually produces the desired effects, calling for consideration of ontological, pedagogical and ethical aspects.

The ontological challenge lies in assessing whether a given athlete has talent and, with a new materialist approach, we can never separate the ontology from the assemblage in which talent is given. Talent is therefore something that a human actor achieves through the interaction between a talent assemblage and a development assemblage-and success can only be determined when the goal of a place in the senior elite is reached. Until that point, some degree of doubt regarding talent potential will necessarily prevail. The athlete and the talent developers therefore work with an object that is ontologically incomplete and which disappears if one or both parties no longer believe that the potential is present and therefore withdraws from the cooperation.

The pedagogical challenge, based on gaining some form of insight into this incompleteness, therefore lies in planning what kind of interaction needs to be established between the athlete and talent developers if talent is to be realized over time in a manner recognized as credible progression towards a place among the elite. This is not a simple matter because talent as a phenomenon is unstable and, inter alia, contingent upon whether the body cooperates or takes another course; for example, becoming injured. Talent development must therefore constantly be monitored, adjusted and revised in order to maintain both physical progression and (a conception of) the existence of talent. 
The ethical challenge lies in the fact that becoming can take multiple directions and possibly point away from the path of talent development. As our analysis shows, the capacity and readiness of the assemblage tend to be limited to statements and signs that fall within the assemblage's own goals and interests because the designated athlete's development is linked to a particular desired future goal that can only be fulfilled if the athlete overrides or postpones other (competing) possible and perhaps simultaneous becomings. In other words, if the human biological material is read as having talent, the talent assemblage tends to exclude other realities and forms of becoming. This happens, for instance, when the talent assemblage dismisses any emerging doubts and thereby maintain the athlete's commitment to becoming part of the elite within the chosen sport.

Jesper Stilling Olesen is associate professor at the Department of Educational Anthropology, the Danish School of Education, Aarhus University in Denmark. Olesen is co-editor of the book Talent development in Danish Public Schools (published in Danish) and the author of several articles about talent development from a new materialist perspective. E-mail: jeo@edu.au.dk

Jens Christian Nielsen, Ph.D., is associate professor in youth studies, Danish School of Education, Aarhus University in Denmark. Jens Christian has published on talent, transitions, belonging and exclusion among young people. His new research project focuses on students wellbeing in a sociomaterial perspective. E-mail: jen@edu.au.dk

Dorte Marie Søndergaard is professor in social psychology, Danish School of Education, Aarhus University in Denmark. She has published on subjectification, marginalization and bullying among children and young people, and on the formation of gender and other social categories. Her new research projects focuses on digital practices among youth and young people living during the crises of Covid 19. E-mail: dms@edu.au.dk

\section{References}

Abbott, A. \& Collins, D. (2004): "Eliminating the dichotomy between theory and practice in talent identification and development: Considering the role of psychology". Journal of Sports Sciences, 22, 395-408.

Alfermann, D., \& Stambulova, N. (2007): "Career transitions and career termination". In G. Tenenbaum \& R. C. Eklund (Eds.), Handbook of sport psychology (pp. 712-733). Hoboken, NJ, US: John Wiley \& Sons Inc.

ATK 2.0 Træning af børn og unge. Team Danmark. Lokaliseret 8.6.2017: http://www. teamdanmark.dk/-/media/9653D3B203264CEA9B94DE0519368F70.ashx.

Baker, J., Cobley, S., Schorer, J. \& N. Wattie. (2017): Routledge Handbook of Talent Identification and Development in Sport. London: Routledge. 


\section{Culture Unbound}

Journal of Current Cultural Research

Bartmus, U., Neumann, E. \& Marées, H. (1987): "The talent problem in sport". International Journal of Sports Medicine, 8, 415-416.

Bloom, B.S. (1985): Developing talent in the young. New York: Ballantine Books.

Bruun Jensen, C. (2010): STS in S. Brinkmann, L. Tanggaard (eds.) Kvalitative metoder. [Qualitative methods] Copenhagen: Hans Reitzels Forlag.

Callon, M. (1984): "Some elements of a sociology of translation: domestication of the scallops and the fishermen of St Brieuc Bay". The Sociological Review. 32(S1): $196-233$

Côtè, J. (1999): "The influence of the family in development of talent in sport". The Sport Psychologist, Vol 13, 395-417.

Csikszentmihalyi, M., Rathunde, K. \& Whalen, S. (1993): Talented teenagers: The roots of success and failure. New York: Cambridge University Press.

Davies, B. (2014): Listening to Children: Being \& becoming. London: Routledge.

Debois, N., A. Ledon \& P. Wylleman (2015): “A lifespan perspective on the dual career of elite male athletes". Psychology of Sport and Exercise. 21, 15-26. Elsevier

Deleuze, G. \& Guattari, F. (1987) [1980]. A Thousand Plateaus: Capitalism and Schizophrenia. Capitalism and Schizophrenia. 2. Minneapolis and London: University of Minnesota Press.

Durand-Bush, N. \& Salmela, J.H. (2002): "The development of talent in sport". In R.N. Singer, H.A. Hausenblas \& C.M. Janelle (Eds.), Handbook of sport psychology (pp. 269-289). New York: Wiley.

Ericsson, K.A., R.T. Krampe \& C. Tesch-Römer, C. (1993): The role of deliberate practice in the acquisition of expert performance. Psychological Review, 100(3), 363-406.

Fox, N. J. \& Alldred, P. (2016): Sociology and the New Materialism: Theory, Research, Action. London: Sage Publications.

Gagné, F. (1993): Constructs and models pertaining to exceptional human abilities. In K.A. Heller, F.J. Mönks \& A.H. Passow (Eds.), International handbook of research and development of giftedness and talent (pp. 63-85). Oxford: Pergamon Press.

Gagné, F. (2000): "Understanding the complete choreography of talent development through DMGT-based analysis". In K.A. Heller (Ed.), International handbook of giftedness and talent (2 $2^{\text {nd }}$ ed., pp. 67-79). Oxford, UK: Elsevier Science Ltd.

Hellstedt, J. (2005): “Invisible Players: A family Systems Model". Clinics in Sports Medicine 24, 899-928.

Henriksen, K: (2010): The ecology of talent development in sport: A multiple case study of successful athletic talent development environments in Scandinavia. $\mathrm{PhD}$. Dissertation. Faculty of health Sciences, University of Southern Denmark.

Latour B (2003): What if We Talked Politics a Little? Contemporary Political Theory 2(2): $143-164$

Latour, B. (1999): Pandora's hope: essays on the reality of science studies. Cambridge, Massachusetts: Harvard University Press.

Law, J. (1992): "Notes on the theory of the actor-network: ordering, strategy and heterogeneity". Systems Practice, 5(4) 379-93.

Law, J. (2009): "Actor-network theory and material semiotics". In: B. Turner (ed.) The new Blackwell companion to social theory. Oxford: Blackwell, pp. 141-58.

Malina, R.M. (1997): "Talent identification and selection in sport". Spotlight on youth sports, 20(1).

Meyer J. P. \& N. J. Allen (1991): “A three-component conceptualization of organizational commitment". I: Human resource management review, Vol. 1, Issue 1, 61-89. Elsevier.

Mol, A. \& Law, J. (2004): Embodied Action, Enacted Bodies: the Example of Hypoglycaemia in Body \& Society. 10(2-3) 43-62.

Mol, A. (1999): “Ontological Politics. A Word and Some Questions". The Sociological Review 47(1): 74-89. 


\section{Culture Unbound}

Journal of Current Cultural Research

Nielsen, J. C., Olesen, J. S. \& Skrubbeltrang, L. S. (2017): Idrcetselevernes tilblivelse og transitioner - Idrcetsklasser som ny standard for tidlig talentudvikling $i$ Danmark. [The becoming of sports students-Sports classes as a new standard for early talent development in Denmark] Aarhus University.

Régnier, G., Salmela, J.H. \& Russell, S.J. (1993): “Talent detection and development in sport". In R.N. Singer, M. Murphey \& I.K. Tennant (Eds.), Handbook of research in sport psychology (pp. 290-313). New York: Macmillan.

Scanlan, T. K., P. J. Carpenter, J. P. Simons, G. W. Schmidt \& B. Keeler (1993): "The Sport Commitment Model: Measurement Development for the Youth-Sport Domain". Journal of sport \& exercise psychology, 15 (1), 16-23.

Skrubbeltrang, L. S., Nielsen, J. C., Olesen, J. (2016): How to stay becoming: living up to the code of conduct in a sports class. Ethnography and Education. Vol/bind: 11 nr. 3, 371-387

Stambulova, N. B., \& Wylleman, P. (2014): “Athletes' career development and transitions". In A. G. Papaioannou \& D. Hackfort (Eds.), Routledge companion to sport and exercise psychology: global perspectives and fundamental concepts. International perspectives on key issues in sport and exercise psychology (pp. 605-620). Hove: Routledge.

Stambulova, N., Alfermann, D., Statler, T. \& Côtè, J. (2009): ISSP Position Stand: Career Development and Transitions of Athletes. In International Journal of Sport and Exercise Psychology. 7, 395-412

Storm, L. K., Henriksen, K \& Christensen, M. K. (2012): "Specialization pathways among elite Danish athletes. A look at the Developmental Model of Sports Participation from a cultural perspective". International Journal of Sport Psychology, 43, 199-223.

Tranckle, P. \& Cushion, J.C. (2012): "Rethinking Giftedness and Talen in Sport". Quest, 58(2), 265-282.

Uprichard, E. (2008). "Children as 'Being and Becoming': Children, Childhood and Temporality". Children \& Society, vol 22, 303-313.

Walters, J. \& Gardner, H. (1986): The crystallising experience: Discovering an intellectual gift. In R. Sternberg \& J. Davidson (Eds.), Concepts of giftedness (pp. 306-331) New York: Cambridge University Press.

Wylleman, P., Alfermann, D., \& Lavallee, D. (2004): “Career transitions in sport: European perspectives". Psychology of Sport and Exercise, 5 (1), 7-20. 